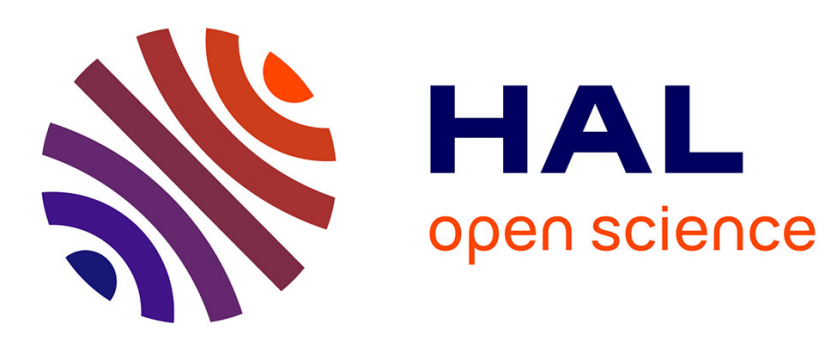

\title{
Softening of the shear modulus C44 in (TaSe4)2I due to sliding charge density waves
}

\author{
R. Britel, M. Saint-Paul, P. Monceau, F. Levy
}

\section{To cite this version:}

R. Britel, M. Saint-Paul, P. Monceau, F. Levy. Softening of the shear modulus C44 in (TaSe4)2I due to sliding charge density waves. Journal de Physique IV Proceedings, 1993, 03 (C2), pp.C2-75-C2-78. 10.1051/jp4:1993215 . jpa-00251584

\section{HAL Id: jpa-00251584 https://hal.science/jpa-00251584}

Submitted on 1 Jan 1993

HAL is a multi-disciplinary open access archive for the deposit and dissemination of scientific research documents, whether they are published or not. The documents may come from teaching and research institutions in France or abroad, or from public or private research centers.
L'archive ouverte pluridisciplinaire HAL, est destinée au dépôt et à la diffusion de documents scientifiques de niveau recherche, publiés ou non, émanant des établissements d'enseignement et de recherche français ou étrangers, des laboratoires publics ou privés. 


\title{
Softening of the shear modulus $\mathrm{C}_{44}$ in $\left(\mathrm{TaSe}_{4}\right)_{2} I$ due to sliding charge density waves
}

\author{
R. BRITEL, M. SAINT-PAUL, P. MONCEAU and F. LEVY*
}

Centre de Recherches sur les Très Basses Températures, Laboratoire associé à l'Université Joseph Fourier, CNRS, BP. 166, 38042 Grenoble cedex 9, France

* Institut de Physique Appliquée, Ecole Polytechnique Fédérale de Lausanne, 1015 Lausanne, Switzerland

\begin{abstract}
Acoustic velocity of the shear mode $\mathrm{C}_{44}$ of quasi-one-dimensional (TaSe 4$)_{2} \mathrm{I}$ has been measured at $15 \mathrm{MHz}$ frequency with the ultrasonic technique. It is found that the elastic constant $\mathrm{C} 44$ decreases when applied electric fields greater than the threshold $E_{T}$ are applied for charge-density wave (CDW) depinning. The decrease $\Delta \mathrm{C}_{44} / \mathrm{C}_{44} \sim 10^{-4}$ observed at $15 \mathrm{MHz}$ for $\mathrm{E} \sim 10 \mathrm{E}_{\mathrm{T}}$ is two orders of magnitude smaller than the decrease reported at low frequency $(\mathrm{kHz})$. Present results are compared with the effects of CDW depinning on the elastic properties predicted by several models.
\end{abstract}

\section{Intoduction}

The phenomenon of sliding charge density wave (CDW) is observed in quasione-dimensional compound such as $\left(\mathrm{TaSe}_{4}\right)_{2} \mathrm{I}$ [1]. The sliding of the CDW is induced by application of an electric field $E$ in excess of a threshold $E_{T}$. The sliding yields a decrease of the electrical resistivity with field which has been reviewed in [1] and is also accompanied by a mechanical effect: the softening in elastic stiffness [2-5]. Most experimental studies have concentrated on the properties of the Young's modulus measured at low frequencies $(\mathrm{kHz})[2,4]$.In this paper we report a study by ultrasonic measurements of the shear modulus $\mathrm{C}_{4} 4$ of ( $\left.\mathrm{TaSe}_{4}\right)_{2} \mathrm{I}$. Elastic constant C44 of $\left(\mathrm{TaSe}_{4}\right)_{2} \mathrm{I}$ has a very small value $1.2 \times 10^{9} \mathrm{~N} / \mathrm{m}^{2}[6]$. Such a small value reflects the weak (Van der Waals) interchain bounding in quasi-one-dimensional compounds [4].

\section{Experimental results}

Large crystals (typical dimension $3 \times 2 \times 2 \mathrm{~mm}^{3}$ ) were used and shear mode with wavevector $\mathbf{q} \perp[001]$ and polarization vector $\mathbf{u} / /[001]$ was generated. This elastic mode corresponds to the elastic constant $\mathrm{C} 44$ with the tetragonal symmetry of $\left(\mathrm{TaSe}_{4}\right)_{2} \mathrm{I}$. Standard pulse echo technique was used at $15 \mathrm{MHz}$ with two $\mathrm{LiNbO}_{3}$ transducers and the sound velocity was measured by a phase coherent detection. The electrical field effect on the sound velocity of the elastic mode C44 $\mathrm{w}$ a s measured with electric field parallel to the caxis. Thin copper film $5000 \AA$ was deposited on the two surfaces perpandicular to the $c$ axis in order to obtain good electrical contacts. Care was taken to avoid spurious effects due to sample heating by the electric pulses. 
We have used an experimental procedure similar to that described in ref 5. A 30 $\mu \mathrm{s}$ wide electric pulse was applied and its position was adjusted in order to cover completely the travel period about $5 \mu \mathrm{s}$ of a selected acoustic echo $1 \mu \mathrm{s}$ wide. Velocity of the selected echo was measured while the electric pulse was progressively delayed until the selected echo was outside the electric pulse. The field effect on the amplitude of the acoustic echo was too small to be accurately measured below the Peierls transition $T_{p}=263 \mathrm{~K}$ electric field effects were observed on both electrical resistance $R$ and sound velocity $V$ as shown in fig 1 . $R$ was deduced from measurements of the electric pulse amplitude $U$.

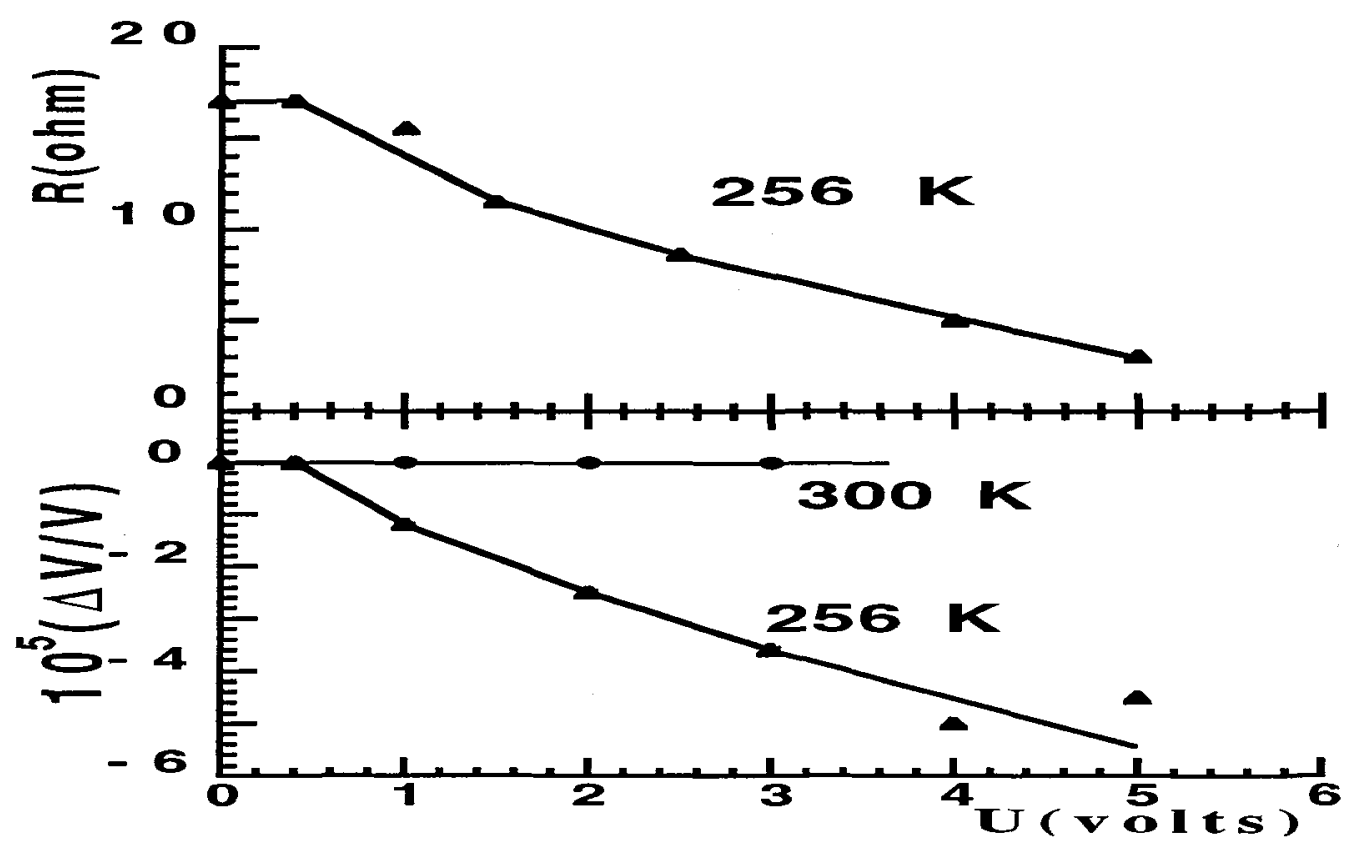

Fig1: Electrical resistance function of voltage and voltage dependence of the sound velocity of the $\mathrm{C} 44$ mode $\mathbf{q} \perp[001]$ and $\mathbf{u} / /$ [001]

The threshold voltage UT is defined as the voltage where electric resistance starts to deviate from the constant ohmic value $R_{0}$ [1]. UT has been shown to exponentially increase when temperature decreases and consequently we have only performed field effect measurements around 250 K.In figl it can be seen that for $U=10 \mathrm{UT}$ the decrease of the sound velocity is $\Delta \mathrm{V} / \mathrm{V} \approx 5 \times 10^{-5}$. The charge density current ICDW was calculated with the relation ICDW $=I-U / R_{0}$, where $I$ is the total current [1].We show in fig2 that the decrease $\Delta \mathrm{V} / \mathrm{V}$ follows the (ICDW) 0.5 law for small ICDW and saturates at high value in fig 2. As do Young's modulus[3] and torsional modulus[4]. 
The shear modulus C44 decreases when CDW slides but the effect measured at high frequency $(15 \mathrm{MHz})$ is two orders of magnitude smaller.than for the other techniques which are performed in the frequency range of $\mathrm{kHz}$.

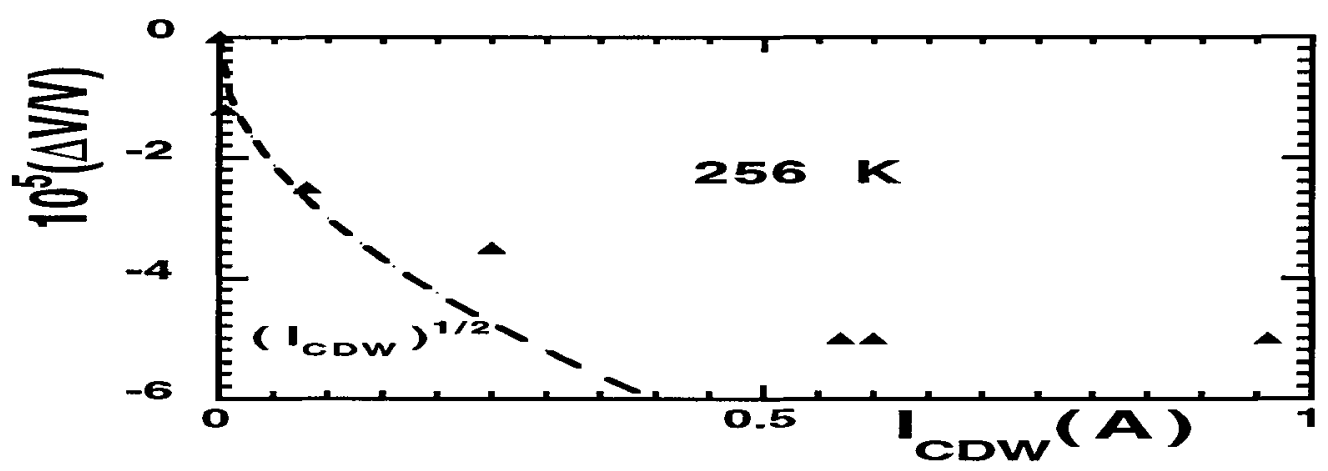

Fig2: Sound velocity changes as a function of the CDW current component.

\section{Discussion and Conclusion}

Present results obtained on $\left(\mathrm{TaSe}_{4}\right)_{2} \mathrm{I}$ at $15 \mathrm{MHz}$ are similar to those found on $\mathrm{TaS}_{3}$ [5] at the same frequency. They confirm the frequency dependence of the field effect on the elastic properties as pointed out in [7] the modulus depinning anomalies decrease with frequency. Several models reviewed in ref [8] have been proposed to explain the elastic behaviour associated with the depinning of the CDW but its interpretation is still uncertain and only qualitative agreements are found. An early proposal was that the acoustic velocity was directly affected by the CDW motion[9] but the predicted shift is too small to explain the measurements.The decoupling model [10] proposed that the CDW must distort with the same wavevector as the underlying lattice because the pinning couples together CDW and lattice,so that the measured stiffness is the sum of the stiffness components $K$ of the CDW and $\mathrm{C}$ of the lattice. Magnitude of the CDW elastic stiffness $\mathrm{K}$ is about one order of magnitude smaller than $\mathrm{C} 44$ [2]. When the CDW slides the net stiffness is reduced. The screening model [11] considers the effect of CDW screening on phonons. It is assumed that while the pinned CDW could not contribute to screening the depinned could and the gradual softening is due to a distribution of threshold fields. Finally relaxational models have been proposed [4,7] to explain the frequency dependence. Softening is due to relaxation of some defects in the CDW, but the microscopic nature of these defects is not known.

Elastic constant $\mathrm{C} 44$ decreases by about $10^{-4}$ with $\mathrm{CDW}$ depinning. This result suggests that CDW motion affects the interchain forces. The decrease of $\mathrm{C} 44$ is probably due to a change in the CDW transverse phase coherence with applied voltage [4]. 
In conclusion explanation of the elastic effects observed in one-dimensional compound such as $\left(\mathrm{TaSe}_{4}\right)_{2} \mathrm{I}$ when the $\mathrm{CDW}$ is put into motion is not satisfactory and measurements in a large frequency range should give useful information.

\section{References}

1- For reviews see $P$. Monceau Electronic properties of inorganic quasi-onedimonsional compound ( Reidel Dordrecht 1985); and G. Grüner Rev Mod Phys $\underline{60}$ 1129 (1988)

2- G. Mozurkewich, P. M. Chaikin, W. G. Clark and G. Grüner Solid State Commun. 56 (1985) 421

3- A. Suzuki, H. Mizubayashi and S. Okuda J. of Phys. Soc. Japan. 57 (1988) 432

4- X.D. Xiang and J.W. Brill Phys.Rev.B $\underline{36}$ (1987) 2969

5- M.H. Jericho and A. M. Simpson Phys.Rev. B 34 (1986) 1116

6- M.Saint-Paul, P. Monceau, and F. Levy Solid StateCommun.67(1988) 581

7_ X.D. Xiang and J.W. Brill Phys.Rev. Lett. 63 (1989) 1853

8-G. Mozurkewich in Perspectives in Physical Acoustics

Editors Y.Fu, R.K.Sundfors and P. Suntharothok (World Scientific 1992)

9- S.N. Coppersmith and C.M. Varma Phys.Rev B $\underline{30}$ (1984) 3566

10- G. Mozurkewich P.M. Chaikin,W.G. Clark, and G. Gruner Solid.Stat. Commun.

56 (1985) 421.

11-K. Maki and A. Virosztek Phys.Rev B $\underline{36(1987)} 2910$ 